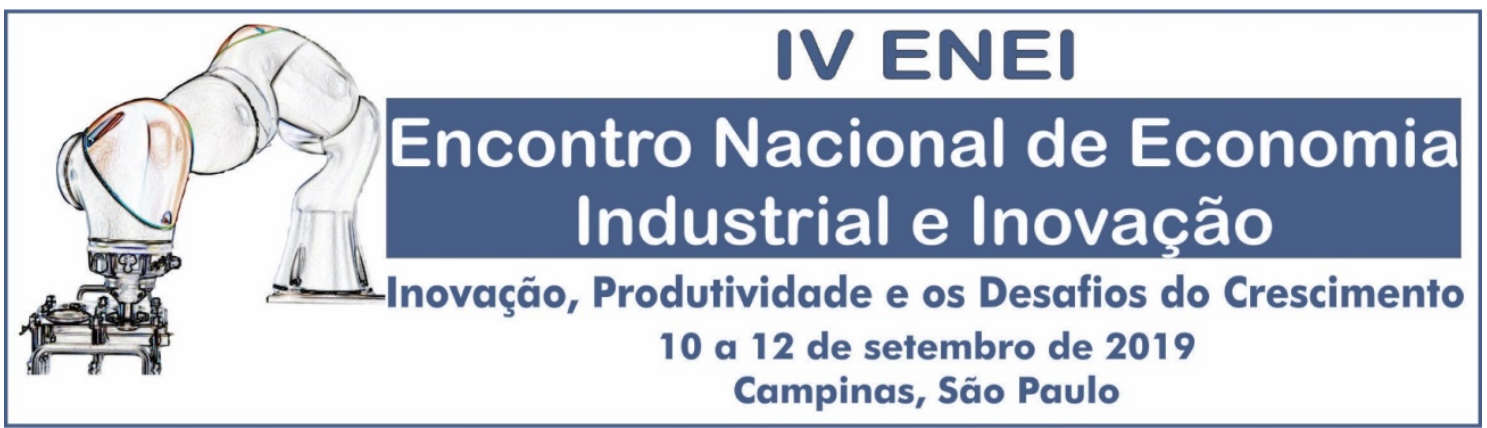

GISELLE CAROLINE MARQUES FERRAZ

ANTÔNIO CARLOS DIEGUES

PLANEJAMENTO ECONÔMICO E POLÍTICA INDUSTRIAL NA CHINA: DOS PLANOS QUINQUENAIS AO MADE IN CHINA 2025

Trabalho submetido para o Encontro Nacional de Economia Industrial e Inovação, a ser realizado em setembro de 2019.

Área temática - 6.1 Políticas Industriais e Comerciais

Campinas, SP

Maio de 2019 


\title{
Planejamento econômico e Política Industrial na China: dos Planos Quinquenais ao Made in China 2025
}

\author{
Giselle Caroline Marques Ferraz ${ }^{1}$ \\ Antônio Carlos Diegues ${ }^{2}$
}

\section{Resumo:}

A tradição de planejamento econômico da China aliada à continuidade proporcionada pelo sistema unipartidário, permitiu que o país executasse um plano de desenvolvimento gradual. As transformações estruturais e a indústria sempre estiveram em foco nos Planos Quinquenais chineses, embora com alvos diferentes no decorrer do tempo. Este trabalho buscará demonstrar como a política industrial chinesa se moldou no decorrer do tempo para que fosse possível uma transformação gradual que culmina na mais recente fase do desenvolvimento chinês: a busca pela endogeneização da inovação tecnológica e o catching up com a indústria 4.0.

Palavras-chave: China, Made in China, planejamento, Planos Quinquenais, indústria.

\begin{abstract}
:
China's tradition of economic planning combined with the continuity provided by the one-party system allowed the country to execute a gradual development plan. Structural transformations and industry have always been in focus in the Chinese Five Year Plans, albeit with different targets over time. This work will seek to demonstrate how Chinese industrial policy has shaped itself over time so that a gradual transformation that culminates in the most recent phase of Chinese development is possible: the quest for the endogenization of technological innovation and the catching up with industry 4.0.
\end{abstract}

Keywords: China, Made in China, planning, five-year plans, industry

\section{Introdução}

A China construiu ao longo de sua história pós-revolução (1949) uma tradição de planejamento econômico. Os Planos Quinquenais chineses, além de uma importante ferramenta para o desenvolvimento, representam um interessante instrumento para analisar e observar a trajetória de desenvolvimento chinesa.

É sabido que o perfil de gestão chinesa apresenta-se sempre voltado para uma estratégia sequencial, seguindo etapas bem estabelecidas e preparando sempre para os próximos passos. A partir da década de 2000, com o desaquecimento da economia chinesa (passando de patamares de crescimento médio anual de $10 \%$, para $7 \%$ ao ano), o governo chinês tem demonstrado que adotará mais uma mudança de trajetória, dessa vez com a política industrial mais voltada para a eficiência produtiva e para a competitividade internacional na questão tecnológica.

É importante destacar que o Estado chinês mantém-se no topo das decisões econômicas e ainda exerce forte influência sobre diversos setores sejam eles econômicos, no controle de empresas/indústrias estratégicas, ou políticos, no controle centralizado nas mãos do PCCh, ou sociais, no controle de mídias e do poderio bélico. Tal capacidade de

\footnotetext{
${ }^{1}$ Mestranda em Desenvolvimento econômico - Universidade Estadual de Campinas (UNICAMP). Email: giselleeferraz@gmail.com

${ }^{2}$ Professor Doutor - Instituto de Economia da Universidade Estadual de Campinas (UNICAMP). E-mail: acdieguesjr@gmail.com
} 
controle e grande presença do Estado faz com que os planos quinquenais chineses tenham grande capacidade de alcance dos resultados propostos.

Acredita-se que as mudanças estratégicas e a sequencialidade podem ser percebidas nos planos quinquenais e que essa nova fase tem exigido da liderança chinesa um esforço adicional: uma política industrial voltada para a inovação. O objetivo deste trabalho é, portanto, apresentar como o foco de política industrial dentro do Planejamento econômico chinês evoluiu desde a implementação do sistema e como essa estratégia culminou no recente plano decenal de política industrial denominado Made in China 2025 .

Para tentar demonstrar tal percepção este trabalho encontra-se dividido em quatro partes. A primeira consiste numa recuperação histórica de como evoluiu o planejamento na China denotando como o Estado mostra-se presente e ativo no direcionamento da economia. Em seguida serão apresentados brevemente os planos quinquenais chineses a partir da perspectiva da indústria, onde poderá ser observada a mudança do foco industrial ao longo dos planos. Ainda no segundo tópico pretende-se mostrar a capacidade de realização do planejamento chinês com comparações metas versus resultados. Na sequência será discutido o plano de política industrial intitulado Made in China. Por fim, as conclusões.

1. Evolução do planejamento e presença do Estado no direcionamento da economia da China

Compreendendo a importância do Estado na implementação do planejamento de longo prazo e da política industrial, esta seção tem como objetivo apresentar como o Estado chinês direcionou o planejamento a partir de 1949 para demonstrar como essa força direcionadora ainda é fundamental para a condução e o sucesso de políticas econômicas, especialmente o planejamento central e a política industrial.

Após a criação da RPC em 1949, a liderança do país lançou planos imperativos, ao estilo soviético, com uma ampla gama de objetivos quantificados. Porém, em dezembro de 1978, os líderes do Partido reconheceram que, para fomentar o crescimento econômico, ao lado do Estado, um papel maior deveria ser desempenhado pelos preços e pelas forças do mercado (BERTOLDI et al 2016). Com o passar do tempo, a natureza imperativa do plano perdeu força, e o foco foi transferido para a mobilização de recursos públicos e privados para atingir metas de desenvolvimento mais amplas. A crescente complexidade da economia chinesa tornou este "planejamento estatal de desenvolvimento", com sua pretensão de ser capaz de escolher os vencedores, menos eficaz. Dado que a China continuou a evoluir para um sistema de economia de mercado, nos últimos anos (em particular durante o $11^{\circ}$ e $12^{\circ}$ planos - 2006 a 2015), o planejamento econômico tornou-se cada vez menos intrusivo e mais indicativo, centrando-se na definição de condições estruturais dentro das quais as forças de mercado operam (pelo menos em alguns setores).

Os primeiros planos eram caracterizados pelo que tornou-se conhecido como "planejamento imperativo" (também conhecido como planejamento diretivo ou obrigatório). Isso significa que o controle administrativo substitui as instituições de mercado e os preços, e o planejador é responsável pela alocação de recursos. 
Após a Segunda Guerra Mundial, a prática de elaboração e implementação desses planos imperativos (geralmente de cinco anos) se espalhou para todos os países governados por regimes comunistas. Entretanto, a falha do "Grande Salto para Frente"3 subsequentemente levou a algum recuo na "profundidade" de aplicação do planejamento imperativo. Este fato também fornece parte da explicação para o porquê Deng Xiaoping e outros líderes do Partido dirigiram uma mudança radical na abordagem econômica após a morte de Mao.

Em consequência, em dezembro de 1978 , no meio da implementação do $5^{\circ}$ Plano Quinquenal, ocorreu uma grande mudança na definição das políticas. A Terceira Sessão Plenária do $11^{\circ}$ Comitê Central do PCCh decidiu mudar o foco do Partido para a modernização. Isso implicou reformas profundas nos âmbitos econômico e social do país, o que, por sua vez, exigiu um relaxamento da "economia de comando" que prevalecia após a criação da RPC. Isso também implicou uma mudança na natureza do exercício de planejamento. O planejamento semelhante ao dos "Estados de desenvolvimento" (por exemplo, Japão, Coréia, Taiwan) seria introduzido ao lado do planejamento imperativo, criando um sistema de planejamento híbrido ${ }^{4}$ (BERTOLDI et al 2016).

O "planejamento estatal do desenvolvimento" reconhece o papel dos preços e das forças de mercado no sistema econômico como um mecanismo chave para coordenar decisões de produção de nível mais baixo, o que em si representa uma grande mudança na ênfase do planejamento imperativo (BERTOLDI et al 2016). Ainda assim, é o Estado que mantém o controle não só das alavancas macroeconômicas do país, mas também de setores estratégicos (diretamente através de empresas estatais ou indiretamente através de orientações administrativas para o setor privado), sendo assim, o Estado direciona ativamente os recursos para os amplos setores considerados essenciais para a realização dos objetivos de desenvolvimento do Estado. Instrumentos como a taxa de câmbio competitiva e a repressão financeira também são usados para atingir esses objetivos.

O planejamento estatal de desenvolvimento foi introduzido pela primeira vez no Japão, Coréia e Taiwan nos anos 1950 e mostrou-se eficaz na gestão da transição rápida desses países, de uma economia emergente para uma economia avançada (no caso do Japão) e do desenvolvimento para economias emergentes (no caso da Coréia e Taiwan). Não surpreendentemente, no processo de reforma econômica e abandono gradual de uma economia dirigida, as autoridades procuraram no exterior pistas sobre como conseguir uma transformação bem-sucedida da economia sem comprometer o papel político fundamental do Partido Comunista Chinês. O papel crescente do setor privado na economia chinesa continuaria sendo orientado e monitorado através do processo de planejamento, mantendo alguns elementos do antigo sistema de planejamento imperativo em setores considerados estratégicos, como indústrias pesadas ou indústrias de rede (BERTOLDI et al 2016).

O planejamento chinês continuou a evoluir. Como as reformas econômicas permitiram que o setor privado prosperasse e o país enfrentasse novos desafios, tanto no plano social quanto ambiental, o plano teve que afrouxar mais algumas de suas características obrigatórias e de desenvolvimento e tornar-se cada vez mais indicativo.

Contrariamente ao planejamento estatal de desenvolvimento (o planejamento ainda mais imperativo), o planejamento indicativo não tenta alocar recursos para atingir certos objetivos de desenvolvimento, mas centra-se mais em agrupamento de informação, formação de expectativas e coordenação de políticas para resolver uma série de falhas

\footnotetext{
${ }^{3}$ Será melhor abordado no próximo tópico.

${ }^{4}$ Mantém dimensões imperativas e de desenvolvimento.
} 
de mercado e definir um ambiente estável, que reduz a incerteza e favorece o crescimento econômico. Em economias em transição como a China (ou em economias de mercado que estão sofrendo importantes transformações depois de uma grande turbulência, como foi o caso das economias da Europa Ocidental após a Segunda Guerra Mundial, como a França, Itália e Holanda), os agentes privados podem ter que enfrentar mais do que informações imperfeitas e expectativas mais voláteis, enquanto os formuladores de políticas podem ter que reduzir estratégias conflitantes, bem como tentar desenvolver sinergias. Nestes casos, o planejamento indicativo, fornecendo o senso de direção da economia e explicando os incentivos para alcançar objetivos e metas de médio prazo, pode ter propriedades que melhoram o bem-estar e a incerteza a médio prazo, criando assim um ambiente mais previsível para o investimento.

Os planos quinquenais chineses mais recentes tornaram-se mais indicativos, no entanto, eles ainda retém algumas características dos antigos planos imperativos, tanto na forma como eles são elaborados como em seu conteúdo. Os planos continuam a ser o documento chave onde a liderança do PCCh, com base numa ampla consulta dentro e fora do partido, esclarece a sua visão sobre a direção econômica do país a médio prazo e indica como consegui-la através de uma série de ferramentas. O plano quinquenal ainda aloca diretamente os recursos e fixa uma série de metas quantitativas para vários setores econômicos, em particular no setor das infraestruturas de investimento, construção e indústrias pesadas. Os objetivos de desenvolvimento continuam a ser importantes, nomeadamente no que diz respeito à modernização industrial e à subida na escala tecnológica. Para certos aspectos, a condução de uma política preocupada com o meio ambiente adotada no $12^{\circ}$ Plano e, a busca pela inserção internacional na questão da tecnologia, no $13^{\circ}$ Plano, podem ser considerada parte dos estágios mais avançados de um planejamento de desenvolvimento.

\section{Histórico: Indústria nos Planos Quinquenais Chineses ${ }^{5}$}

Pretende-se aqui fazer uma recuperação histórica dos Planos Quinquenais chineses ${ }^{6}$ com foco nas suas metas e objetivos voltados para a indústria e para a inovação ${ }^{7}$. Isso se deve ao fato de que o objetivo deste trabalho é demonstrar como a mudança de foco da política industrial chinesa ao longo dos anos é perceptível nos planos quinquenais, mudança esta que culmina em uma PI voltada para a endogeneização da inovação tecnológica demonstrada no Made in China 2025.

\footnotetext{
${ }^{5}$ É importante ressaltar que outras importantes medidas de política industrial como o Plano Nacional de Longo Prazo para Ciência e Tecnologia (2006-2020) e a política de indústrias emergentes de 2009, além de outras iniciativas que também buscaram favorecer setores mais tradicionais, com estímulo à modernização tecnológica e ao desenvolvimento da capacidade de inovação das empresas, como o programa Reestruturação e Modernização lançado pelo Conselho de Estado, foram também fundamentais, entretanto não são o foco deste trabalho. Para mais detalhes sobre estes programas ver Delgado (2015).

${ }^{6}$ Do $1^{\circ}$ ao $10^{\circ}$ Plano Quinquenal tem-se como fonte o china.org.cn, site autorizado pelo governo chinês, com todas as publicações supervisionadas pelo Escritório do Conselho de Estado de Informação e do China International Publishing Group (CIPG) em Pequim. Isto se deve à restrição de informações do governo Chinês e à inexistência de tradução dos planos na íntegra do mandarim para o português, inglês ou espanhol ou qualquer outra referência que trate destes planos detalhadamente das metas e resultados destes primeiros planos (todos os trabalhos consultados que tratam de alguma forma dos planos ou tem como fonte o mesmo site referido, ou tem sites do governo chinês que estão em mandarim). Já para os demais planos encontraram-se fontes acadêmicas mais detalhadas do que o disponibilizado (e acessível: em inglês e permitido para estrangeiros) pelo governo chinês, portanto estas serão citadas em cada plano.

7 a versão estendida dos Planos Quinquenais com todas as metas, objetivos e resultados pode ser consultada em Ferraz (2017).
} 
Sobre PI e planejamento econômico, Delgado (2015) ressalta que:

Além da articulação entre os organismos de governo para formulação
e condução da política industrial chinesa, sua sustentação é construída
através do sistema de "consenso estruturado", que vertebra a relação
do Estado com os agentes econômicos e a sociedade na China.
Diretrizes germinadas no Partido Comunista irradiam-se pela estrutura
do Estado, sob a liderança do Conselho de Estado (Miller, 2008;
Saich, 2011; Lawrence e Martin, 2013). Diversas agências então as
reelaboram, refinam e especificam, num amplo processo de
convencimento de - e consulta a - esferas variadas da sociedade
chinesa - associações acadêmicas, profissionais e empresariais;
conferências nacionais e regionais; e mídia -, até a formatação
definitiva da política. (Delgado, 2015).

Visto isso, pode-se seguir para o detalhamento histórico. No primeiro Plano Quinquenal da China (1953-1957), o objetivo era lutar por uma alta taxa de crescimento econômico e enfatizar o desenvolvimento da indústria pesada (mineração, fabricação de ferro e aço) e tecnologia. Para isso, as principais tarefas eram voltadas a estabelecer as bases primárias para a industrialização socialista da China, além de inserir a indústria e o comércio no caminho do capitalismo de Estado para facilitar a transformação socialista da indústria privada e do comércio.

A produção combinada das economias estatais, cooperativas e empresas de propriedade estatal-privada aumentou a renda nacional de $21,3 \%$ em 1952 para 92,9\% em 1957 . O investimento acumulado na construção de capital foi de 55 bilhões de yuans e os aumentos de ativos fixos atingiram 46,05 bilhões de yuans, 1,9 vezes mais do que no final de 1952. Cerca de 600 projetos grandes e médios foram concluídos e colocados em produção, estabelecendo a estrutura da industrialização chinesa. $\mathrm{O}$ valor bruto dos produtos industriais em 1957 aumentou 128,6\% a partir de 1952. O valor bruto da produção da indústria e da agricultura aumentou de 30\% em 1949 para 56,5\% em 1957, enquanto o da indústria pesada aumentou de $26,4 \%$ para $48,4 \%{ }^{8}$.

O principal problema que surgiu com essa estratégia foi que a produção agrícola não conseguiu acompanhar a produção industrial. O Plano considerou o valor da produção industrial bruta responsável por $70 \%$ do valor bruto de produção da indústria e da agricultura e os meios de produção representam $60 \%$ do valor da produção industrial bruta como indicadores da modernização industrial, ignorando o desenvolvimento da agricultura.

No $2^{\circ}$ Plano Quinquenal (1958-1962), as tarefas apontavam para continuar a formação industrial com foco na indústria pesada, impulsionar a reconstrução técnica e estabelecer uma base sólida para a industrialização socialista da China. Tendo a construção básica e transformação socialista já estabelecida, o Plano visa buscar impulsionar ainda mais a indústria, agricultura, artesanato, transporte e comércio.

Ainda sobre o $2^{\circ}$ Plano, o mesmo propunha também reforçar a investigação científica para satisfazer as necessidades do desenvolvimento econômico e cultural socialista. Além disso, buscará, a partir do desenvolvimento industrial e agrícola básico, fortalecer a defesa nacional e melhorar o nível de vida das pessoas e a consciência cultural. Neste período o valor da produção industrial dobrou e o investimento na formação de capital subiu de $35 \%$ para $40 \%$ no primeiro período do Plano Quinquenal.

\footnotetext{
${ }^{8}$ Estes dados são fornecidos na fonte, china.org.cn.
} 
Já o $3^{\circ}$ Plano Quinquenal (1966-1970) ${ }^{9}$ tratou de atender as necessidades da população, fortalecer a defesa nacional e esforçar-se para fazer avanços na tecnologia. Quanto à indústria, visa melhorar a infraestrutura, continuar a melhorar a qualidade da produção, aumentar a variedade de produção e quantidade, construir uma economia de autossuficiência e desenvolver o transporte, comércio, cultura, educação e pesquisa científica.

De acordo com o relatório do plano, todos os principais indicadores econômicos foram cumpridos de acordo com o plano. $\mathrm{O}$ valor bruto da produção da indústria e da agricultura ultrapassou as metas em 14,1\%; o valor bruto de produção da agricultura foi de $2,2 \%$ acima da meta; $\mathrm{E}$ o valor bruto da produção da indústria foi $21,1 \%$ acima da meta $^{10}$.

O $4^{\circ}$ Plano Quinquenal (1971-1975) propunha assegurar que a taxa média anual de crescimento do valor bruto de produção da indústria e da agricultura chegasse a 12,5\%. Já o $5^{\circ}$ Plano Quinquenal (1976 - 1980) tinha como foco a modernização e estabelecer um sistema industrial independente.

O $6^{\circ}$ Plano Quinquenal (1981-1985) buscava colocar o desenvolvimento econômico nacional em uma trilha mais estável e saudável. Sendo assim, os objetivos gerais do Plano eram: prosseguir o princípio de "ajustar, reformar, corrigir e melhorar"; superar os vários desafios ao desenvolvimento econômico e estabelecer uma base sólida para o avanço do desenvolvimento econômico e social nacional no próximo período de planejamento.

O plano supracitado tinha como objetivos específicos: alcançar uma taxa de crescimento anual média de 5\% para os produtos industriais e agrícolas; incentivar e implementar a atualização tecnológica das empresas, priorizando a poupança de energia e reunir o capital necessário para reforçar a construção de projetos-chave de energia e comunicação, em preparação ao $7^{\circ}$ Plano Quinquenal; reunir os conhecimentos científicos e tecnológicos do país para a investigação científica e tecnológica e promover a aplicação de novas tecnologias; fortalecer a construção da indústria de defesa nacional, reforçando as forças defensivas nacionais; fortalecer a produção e melhorar a eficiência econômica; desenvolver vigorosamente o comércio, fazer uso efetivo de capital estrangeiro e introduzir ativamente tecnologia avançada para atender às necessidades domésticas.

No $7^{\circ}$ Plano Quinquenal (1986-1990), os princípios e diretrizes fundamentais que se relacionam com a indústria incluíam melhorar a eficiência econômica, especialmente a da qualidade dos produtos; adaptar-se à estrutura em mutação da demanda social e às exigências da modernização econômica, ajustando ainda mais a estrutura industrial; regular os investimentos em ativos fixos, reajustar a estrutura de investimentos e acelerar a construção das indústrias de energia, comunicações, telecomunicações e matérias-primas; mudar o foco da construção para a atualização técnica, reforma e ampliação das empresas existentes; promover o desenvolvimento da ciência e da educação; ampliar a abertura econômica, combinando o crescimento econômico doméstico com a expansão das trocas econômicas e tecnológicas externas;

\footnotetext{
${ }^{9}$ Com a falha do "Grande Salto", nome dado ao $2^{\circ}$ Plano, o mesmo foi interrompido em 1962, e nos anos seguintes (1963-1965) o país buscou reparar os danos causados no período e começou novos estudos para o próximo plano quinquenal.

${ }^{10}$ Apesar de coincidir com o início da Revolução Cultural (1966-1976), a qual acarretou consequências para a sociedade e a cultura da China, indústria e agricultura cresceram a um ritmo elevado durante este período, superando as expectativas oficiais, e logo favorecendo o crescimento econômico.
} 
Para o $8^{\circ}$ Plano Quinquenal (1991-1995), só estão disponíveis os resultados, ainda que o foco principal desta sessão seja analisar as metas. Deste modo aqui serão descritas os principais resultados da indústria, pois se subentende que os resultados descritos pelo governo chinês estão diretamente associados às metas do plano. O investimento total em ativos fixos durante este tempo atingiu 3,89 trilhões de yuans, com uma taxa de crescimento anual de $17,9 \%$ - 13,6 pontos percentuais acima do período de planejamento anterior. Destes, os investimentos nas unidades estatais tiveram um crescimento anual de $22,9 \%$, muito acima do crescimento médio de $4,1 \%$ anterior.

Foram concluídos e colocados em atividade 845 projetos de infraestrutura de grande e médio porte, bem como 374 projetos de inovação tecnológica. Em termos de infraestrutura de transporte, foram construídos 5.800 quilômetros de trilhos, 3.400 quilômetros de linhas duplas e 2.600 quilômetros de ferrovias eletrificadas. Os comprimentos de estrada foram aumentados em 105.000 quilômetros, incluindo 1.600 quilômetros de rodovias.

O valor da produção da indústria primária aumentou a uma taxa anual de 4,1\%, a indústria secundária a uma taxa de $17,3 \%$ e a indústria terciária a uma taxa de 9,5\%. A composição da produção dos três setores foi de 20,3\%: 47,7\%: $32,0 \%$; sendo que no final do $6^{\circ}$ Plano foi de 28,4\%: 43,1\%: 28,5\%; e de 27,1\%: 41,6\%: $31,3 \%$ no final do $7^{\circ}$ plano, respectivamente.

Registraram-se também progressos significativos na reforma do sistema econômico. Mais de 1.100 cidades em nível de condado foram abertas ao mundo exterior, e 13 zonas unidas e outras muitas zonas de desenvolvimento econômico ${ }^{11}$ foram criadas.

Enquanto isso, no $9^{\circ}$ Plano Quinquenal (1996-2000), as tarefas básicas estabelecidas foram completar a segunda fase da modernização e acelerar o estabelecimento de um sistema empresarial moderno. No $10^{\circ}$ Plano Quinquenal (2001-2005), as metas básicas definidas foram: otimizar a estrutura industrial e fortalecer a competitividade internacional da China; atingir o crescimento das indústrias primária, secundária e terciária às taxas de 13,51 e 36 por cento, respectivamente; melhorar a economia nacional e os níveis de tecnologia; aumentar o financiamento de P\&D para mais de $1,5 \%$ do PIB e reforçar as capacidades de inovação científico-tecnológica, acelerando assim o progresso tecnológico.

O documento do $11^{\circ}$ Plano Quinquenal (2006-2010) ${ }^{12}$ reitera do dois princípios para o desenvolvimento - o "conceito de desenvolvimento científico" e a construção de "uma sociedade socialista" - que se tornaram a base do Plano. Segundo Delgado (2015) neste plano:

projetava-se que a nova etapa de desenvolvimento deveria concentrarse menos nas exportações e mais no mercado interno; menos no investimento e mais no consumo, o que conferia especial importância às políticas de garantia de renda e expansão de proteção social, saúde e previdência, que seriam implementadas ao longo do período, além de ações para regular o superinvestimento, especialmente por parte das províncias, mediante rigorosa supervisão do sistema bancário e acentuação do peso do centro na organização política chinesa. O desenvolvimento científico, por sua vez, seria materializado na política de inovação endógena, com a qual a China buscava alterar sua posição nas cadeias internacionais de valor, internalizando parte de

\footnotetext{
11 São as chamas Zonas Econômicas Especiais (ZEE's) onde empresas estrangeiras poderiam operar livremente com o objetivo de atrair investimento estrangeiro e facilitar a transferência e absorção de tecnologia na China. Essas políticas visavam o crescimento e, ao mesmo tempo, não ameaçavam a capacidade geral do governo para gerenciar e dirigir a economia.

12 (FAN, 2006)
} 
suas etapas, além de acentuar a capacidade de inovação do país, bem como edificar setores industriais que sinalizassem para a ocupação de posições de destaque no futuro (DELGADO, 2015, p 17)

Já no $12^{\circ}$ Plano Quinquenal (2011-2015) ${ }^{13}$, apontava-se que avanços deveriam ser feitos em novas indústrias estratégicas. As despesas com pesquisa e desenvolvimento, em percentagem do $\mathrm{PIB}$, deveriam atingir $2,2 \%$ e o número de registos de patentes deverá aumentar 1,6\% ao ano durante o período de cinco anos. Este plano:

\begin{abstract}
reitera a ênfase no desenvolvimento científico, destaca que o "objetivo fundamental" da transformação econômica deve ser a "melhoria da vida do povo", com "provisão de serviços públicos para todos os cidadãos" e a "reforma no sistema de distribuição de renda". Reafirma, também, o compromisso com a continuidade das reformas econômicas, a expansão da demanda doméstica e a definição clara do alcance do investimento público, para contenção da "expansão às cegas e das construções repetidas". Por fim, além de firmar objetivos para o meio ambiente, o desenvolvimento regional, a construção de um "novo campo socialista", a reestruturação das indústrias-chave, entre outros propósitos, o XII Plano Quinquenal destaca a importância de fortalecer os setores emergentes estratégicos, projetando o objetivo de ultrapassagem nas indústrias neles inscritas, com a fixação da meta de $8 \%$ de sua participação no PIB no período do plano, valendo-se do fortalecimento das medidas de apoio e direção política, da definição de fundos especiais e da expansão do peso do governo nos investimentos iniciais das indústrias nascentes, com a utilização ampla de financiamento preferencial para compensação de riscos, aceleração do uso de standards e aperfeiçoamento da infraestrutura necessária. (Delgado, 2015, p 21)
\end{abstract}

Por fim, no último plano quinquenal ainda em vigor, o $13^{\circ}$ (2016-2020), encontram-se cinco princípios que sustentam as políticas para o desenvolvimento futuro da China. Nenhuma dessas idéias são novas, mas foram colocadas em destaque pela primeira vez. Tais princípios visam trabalhar em conjunto para atingir o objetivo geral de criar "uma sociedade moderadamente próspera". O primeiro princípio é a inovação, principalmente como um motor do desenvolvimento econômico e norteador da estrutura econômica da China para um padrão de crescimento de alta qualidade. O documento promete ainda abertura, afirmando que a China deve utilizar os mercados nacionais e globais e ser mais ativa na governança global. $\mathrm{O}$ "desenvolvimento verde" significa dar continuidade a um crescimento econômico que respeite o meio ambiente. Também é enfatizada a coordenação para assegurar um desenvolvimento equilibrado entre as áreas rurais e urbanas e entre diferentes indústrias. Em conclusão, a China quer garantir que a prosperidade seja compartilhada entre toda a população com um desenvolvimento inclusivo que expanda os serviços sociais. Cinquenta itens práticos, incluindo estratégias, planos e políticas específicas, são definidos no $13^{\mathrm{a}}$ Plano, incorporando estes princípios de desenvolvimento (KENNEDY e JOHNSON, 2016).

A seguir, serão apresentados as principais metas de desenvolvimento apontadas no $13^{\circ}$ plano quinquenal (Quadro 1) .

Quadro 1: Principais Indicadores de Desenvolvimento Econômico e Social para o período do $13^{\circ}$ Plano Quinquenal

\begin{tabular}{|l|l|l|l|l|}
\hline Indicador & 2015 & $\mathbf{2 0 2 0}$ & $\begin{array}{l}\text { Média dos 5 anos } \\
\text { [total cumulativo } \\
\text { dos 5 anos] }\end{array}$ & $\begin{array}{l}\text { Tipo de } \\
\text { meta }\end{array}$ \\
\hline
\end{tabular}

${ }^{13}$ (FAN e HE, 2013). 


\begin{tabular}{|c|c|c|c|c|c|}
\hline \multicolumn{6}{|c|}{ Desenvolvimento Econômico } \\
\hline PIB (trilhões d & yuan) & 67,7 & $>92,7$ & $>6,5 \%$ & \multirow[t]{5}{*}{$\mathrm{E}$} \\
\hline $\begin{array}{l}\text { Produtividade } \\
\text { por pessoa emp }\end{array}$ & $\begin{array}{l}\text { otal do trabalho (10.000 yuan } \\
\text { regada) }\end{array}$ & 8,7 & $>12$ & $>6,6 \%$ & \\
\hline \multirow[t]{2}{*}{ Urbanização } & \begin{tabular}{|ll}
$\begin{array}{l}\text { Residentes } \\
\text { permanentes (\%) }\end{array}$ & Urbanos \\
\end{tabular} & 56,1 & 60 & {$[3,9]$} & \\
\hline & $\begin{array}{l}\text { Residentes } \\
\text { registrados (\%) }\end{array}$ & 39,9 & 45 & {$[5,1]$} & \\
\hline \multicolumn{2}{|c|}{$\begin{array}{l}\text { Valor adicionado do setor de serviços (\% do } \\
\text { PIB) }\end{array}$} & 50,5 & 56 & {$[5,5]$} & \\
\hline \multicolumn{6}{|c|}{ Desenvolvimento orientado para a inovação } \\
\hline \multicolumn{2}{|c|}{ Gasto com P\&D (\% do PIB) } & 2,1 & 2,5 & {$[0,4]$} & \multirow[t]{5}{*}{$\mathrm{E}$} \\
\hline \multicolumn{2}{|c|}{ Patentes por 10000 pessoas } & 6,3 & 12 & {$[5,7]$} & \\
\hline \multicolumn{2}{|c|}{$\begin{array}{l}\text { Contribuição dos avanços científicos e } \\
\text { tecnológicos para o crescimento econômico } \\
(\%)\end{array}$} & 55,3 & 60 & {$[4,7]$} & \\
\hline \multirow[t]{2}{*}{$\begin{array}{l}\text { Acesso à } \\
\text { internet }\end{array}$} & $\begin{array}{l}\text { Casas com banda larga fixa } \\
(\%)\end{array}$ & 40 & 70 & {$[30]$} & \\
\hline & Usuários de internet móvel & 57 & 85 & {$[28]$} & \\
\hline
\end{tabular}

Fonte: KENNEDY e JOHNSON (2016, p 24) (tradução própria)

\subsection{Metas versus resultado}

Devido a escassez de dados e informações sobre todos os planos quinquenais chineses nesta sessão serão apresentados dados para as metas e resultados dos dois últimos planos quinquenais (o $13^{\circ}$ Plano ainda está em vigor) com o objetivo de demonstrar a capacidade de realização dos planos.

No quadro 2 pode-se verificar que poucas das metas analisadas ficaram abaixo do proposto, sendo estas com menos de 1 ponto percentual abaixo da meta. Todos os demais resultados foram alcançados.

Quadro 2: Principais metas e realizações do $11^{\circ}$ Plano Quinquenal (2006-2010)

\begin{tabular}{|l|c|c|c|c|c|}
\hline & $\begin{array}{c}\text { Meta } \\
2010\end{array}$ & $\begin{array}{c}\text { Meta de } \\
\text { aumento }\end{array}$ & $\begin{array}{c}\text { Realizado } \\
2010\end{array}$ & $\begin{array}{c}\text { Aumento } \\
\text { realizado }\end{array}$ & Resultado \\
\hline PIB (trilhões) & - & $7,5 \% /$ ano & 39,8 & $11,2 \% /$ ano & Superado \\
\hline PIB per capita & - & $6,6 \% /$ ano & 29748 & $10,6 \% /$ ano & Superado \\
\hline $\begin{array}{l}\text { Aumento no setor de serviços } \\
\text { (\% da produção) }\end{array}$ & - & $3 \%$ & $43 \%$ & $2,5 \%$ & Abaixo \\
\hline $\begin{array}{l}\text { Aumento do emprego no setor } \\
\text { serviço (\% do total) }\end{array}$ & - & $4 \%$ & $34,8 \%$ & $3,5 \%$ & Abaixo \\
\hline Gasto com pesquisa (\% do PIB) & $2 \%$ & $0,7 \%$ & $1,75 \%$ & $0,45 \%$ & Abaixo \\
\hline Taxa de urbanização & $47 \%$ & $4 \%$ & $47,5 \%$ & $4,5 \%$ & Superado \\
\hline População (10.000) & 13600 & $<8 \%$ & 134100 & $5,1 \%$ & Atingido \\
\hline Redução do uso de energia & 1,2 & $-0,3 \% /$ ano & 1,212 & $-0,13 \% /$ ano & Abaixo \\
\hline $\begin{array}{l}\text { Terra cultivada (100 milhões de } \\
\text { hectares) }\end{array}$ & - & $10 \% /$ ano & - & $14,29 \% /$ ano & Superado \\
\hline Redução na emissão de CO2 & $0,5 \% /$ ano & 9 & $0,5 \% /$ ano & Atingido \\
\hline $\begin{array}{l}\text { Anos de escolaridade (média da } \\
\text { população) }\end{array}$ & 9 & $5,1 \% /$ ano & 2,57 & $8,1 \% /$ ano & Superado \\
\hline $\begin{array}{l}\text { Cobertura de seguro de } \\
\text { aposentadoria urbana (100 } \\
\text { milhões) }\end{array}$ & 2,23 & & & & \\
\hline Cobertura do seguro de saúde & $>80 \%$ & $>56,5 \% / a$ & $96,3 \%$ & $>72,8 \% /$ ano & Superado \\
\hline
\end{tabular}




\begin{tabular}{|l|c|c|c|c|c|}
\hline rural & & no & & & \\
\hline $\begin{array}{l}\text { Aumento no emprego urbano } \\
(10000)\end{array}$ & - & 4500 & - & 5771 & Superado \\
\hline Taxa de desemprego urbano & $5 \%$ & & $4,1 \%$ & - & Superado \\
\hline $\begin{array}{l}\text { Renda per capita disponível } \\
\text { (urbano) }\end{array}$ & - & $5 \% /$ ano & 19109 & $9,7 \% /$ ano & Superado \\
\hline $\begin{array}{l}\text { Rendimento líquido rural per } \\
\text { capita }\end{array}$ & - & $5 \% /$ ano & 5919 & $8,9 \% /$ ano & Superado \\
\hline
\end{tabular}

Fonte: CHOW, 2011. p 4 (tradução própria)

O quadro 3 mostra as principais metas e realizações do $12^{\circ}$ Plano Quinquenal (20112015) onde todas as metas consideradas ou foram atingidas ou foram superadas.

Quadro 3: Principais Metas e realizações do $12^{\circ}$ Plano Quinquenal (2011-2015)

\begin{tabular}{|c|c|c|c|c|c|c|}
\hline & \multicolumn{2}{|c|}{ Meta } & \multicolumn{2}{|c|}{ Realizado } & \multirow[t]{2}{*}{ Resultado } \\
\hline & & 2015 & Crescimento & 2015 & Crescimento & \\
\hline \multicolumn{7}{|c|}{ A economia } \\
\hline \multicolumn{2}{|c|}{ PIB (trilhões de yuan e \%) } & - & 7 & 67,7 & 7,8 & Superado \\
\hline \multicolumn{2}{|c|}{ Serviços/PIB (\%) } & 47 & [4] & 50,5 & - & Superado \\
\hline \multicolumn{2}{|c|}{ Urbanização (\%) } & 51,5 & [4] & 56,1 & - & Superado \\
\hline \multicolumn{7}{|c|}{ Ciência e Tecnologia } \\
\hline \multicolumn{2}{|c|}{ Gasto com P\&D/PIB (\%) } & 2,2 & {$[0,45]$} & 2,2 & - & Atingido \\
\hline \multicolumn{2}{|c|}{$\begin{array}{l}\text { Matrículas no ensino médio } \\
(\%)\end{array}$} & 87 & {$[4,5]$} & 87 & {$[4,5]$} & Atingido \\
\hline \multicolumn{2}{|c|}{$\begin{array}{l}\text { Taxa de educação obrigatória } \\
\text { de nove anos (\%) }\end{array}$} & 93 & {$[3,3]$} & 93 & {$[3,3]$} & Atingido \\
\hline \multicolumn{2}{|c|}{$\begin{array}{l}\text { Invenção de patentes } / 10000 \\
\text { pessoas }\end{array}$} & 3,3 & {$[1,6]$} & 6,3 & - & Superado \\
\hline \multicolumn{7}{|c|}{ Bem-estar social } \\
\hline \multicolumn{2}{|c|}{ População (bilhões) } & $<1,39$ & $<0,72 \%$ & 1,375 & - & Atingido \\
\hline \multicolumn{2}{|c|}{$\begin{array}{l}\text { Renda per capita disponível } \\
\text { dos residentes urbanos (yuan) }\end{array}$} & $>26810$ & $>7 \%$ & - & $7,7 \%$ & Atingido \\
\hline \multicolumn{2}{|c|}{$\begin{array}{l}\text { Renda per capita líquida de } \\
\text { residentes rurais (yuan) }\end{array}$} & $>8,310$ & $>7 \%$ & - & $9,6 \%$ & Atingido \\
\hline \multicolumn{2}{|c|}{$\begin{array}{ll}\text { Novos trabalhos } & \text { urbanos } \\
\text { (milhões) } & \end{array}$} & - & {$[45]$} & - & {$[64,31]$} & Superado \\
\hline \multicolumn{2}{|c|}{$\begin{array}{l}\text { Taxa de desemprego urbano } \\
\text { registrada }(\%)\end{array}$} & $<5$ & - & 4,05 & - & Atingido \\
\hline \multicolumn{2}{|c|}{$\begin{array}{l}\text { Cobertura da pensão básica } \\
\text { para idosos urbanos (milhões) }\end{array}$} & 357 & [1] & 377 & - & Superado \\
\hline \multicolumn{2}{|c|}{$\begin{array}{l}\text { Cobertura do sistema de } \\
\text { seguro de saúde de três pontos } \\
\text { rural }(\%)\end{array}$} & - & [3] & - & {$[>3]$} & Superado \\
\hline \multicolumn{2}{|c|}{$\begin{array}{l}\text { Desenvolvimento de } \text { unidades } \\
\text { de habitação a preços } \\
\text { acessíveis (milhões) }\end{array}$} & - & [36] & - & {$[40,13]$} & Superado \\
\hline \multicolumn{2}{|c|}{$\begin{array}{l}\text { Aumento na expectativa de } \\
\text { vida (anos) }\end{array}$} & 74,5 & {$[1]$} & 76,34 & - & Superado \\
\hline \multicolumn{7}{|c|}{ Recursos e Meio ambiente } \\
\hline \multirow{3}{*}{$\begin{array}{l}\text { Redução } \\
\text { dos } \\
\text { maiores } \\
\text { poluentes } \\
(\%)\end{array}$} & $\begin{array}{l}\text { Demanda de } \\
\text { oxigênio } \\
\text { químico } \\
\end{array}$ & - & [8] & - & {$[12,9]$} & Superado \\
\hline & $\begin{array}{l}\text { Dióxido } \\
\text { sulfúrico }\end{array}$ & - & [8] & - & {$[18]$} & Superado \\
\hline & $\begin{array}{l}\text { Nitrato } \\
\text { amônia }\end{array}$ & - & [10] & - & [13] & Superado \\
\hline
\end{tabular}




\begin{tabular}{|l|c|c|c|c|c|}
\hline \multicolumn{1}{|l|}{$\begin{array}{l}\text { Óxido de } \\
\text { nitrogênio }\end{array}$} & - & {$[10]$} & - & {$[18,6]$} & Superado \\
\hline Cobertura florestal (\%) & 21,66 & {$[1,3]$} & 21,66 & {$[1,3]$} & Atingido \\
\hline $\begin{array}{l}\text { Redução no consumo de } \\
\text { energia/PIB (\%) }\end{array}$ & - & {$[16]$} & - & {$[18,2]$} & Superado \\
\hline $\begin{array}{l}\text { Redução no consumo de água/ } \\
\text { unidade do valor adicionado } \\
\text { industrial (\%) }\end{array}$ & - & {$[30]$} & - & {$[35]$} & Superado \\
\hline $\begin{array}{l}\text { Efetivo uso da água de } \\
\text { irrigação (coeficiente de } \\
\text { utilização) }\end{array}$ & 0,53 & {$[0,03]$} & 0,532 & - & Atingido \\
\hline $\begin{array}{l}\text { Redução da emissão de } \\
\text { CO2/PIB (\%) }\end{array}$ & - & {$[17]$} & - & {$[20]$} & Superado \\
\hline $\begin{array}{l}\text { Área total de terra cultivada } \\
\text { bilhões de metros quadrados) }\end{array}$ & 1,212 & {$[0]$} & 1,243 & - & Superado \\
\hline $\begin{array}{l}\text { Combustível nánil/consumo de energia } \\
\text { fóssil/con } \\
\text { primária (\%) }\end{array}$ & 11,4 & {$[3,1]$} & 12 & - & Superado \\
\hline
\end{tabular}

*[ ] significam que os números são cumulativos ao longo do período quinquenal Fonte: KENNEDY E JOHNSON, 2016. p 24 (tradução própria)

\subsection{Análise}

Pode-se notar com das decrições dos planos que o desenvolvimento chinês foi planejado seguindo etapas muito claras: desenvolveu capacitade instalada industrial buscando primeiro desenvolver sua indústria de base, passando depois para uma fase de modernização da sua estrutura industrial para o catching up com as grandes economias a princípio absorvendo tecnologia e, por último, tentando realizar a endogeneização da inovação tecnológica. Além disso, viu-se que os planos tem capacidade de realização, e atingem ou ficam muito próximos às metas previstas.

Masiero e Coelho (2014) já haviam notado algumas viradas da estratégia de política industrial chinesa a partir dos planos quinquenais. Os autores demonstram a ideia de que a estratégia do Estado chinês consistia em solidificar as bases da industrialização do país focadas em "estimular setores dinamizadores e criar condições estruturais e microeconômicas para o desenvolvimento competitivo dessas indústrias" (p 145). Além disso, dividem as políticas industriais do período pós-reformas em quatro ciclos (19911995; 1996-2001; 2001-2005; 2006-2010):

No primeiro ciclo, as ações possuíram sua consecução dada com forte participação do Estado, que passa a ser decisivo na alocação dos recursos, sendo responsável pelo provimento de infraestrutura, fornecimento de energia e matérias-primas, além de subsidiar sua base tecnológica via importação de bens de produção de alta tecnologia, principalmente no setor metal-mecânico, com vistas a incrementar a manufatura para bens exportáveis com maior valor agregado. Já o segundo ciclo foi marcado pela determinação de metas de longo prazo, com fortes intervenções governamentais de curto prazo, no qual se buscou otimizar a estrutura industrial dos setores considerados prioritários no primeiro ciclo e em processo de consolidação no posterior por meio da promoção de economias de escala e da reorganização produtiva, que seriam dadas com a formação de grandes empresas e grupos empresariais [...] Posteriormente, a China promoveu nova fase de sua política industrial por meio de mais dois ciclos, do Décimo (2001-2005) e Décimo Primeiro Planos (20062010), com vistas a acelerar o desenvolvimento da competitividade de 
seus setores eleitos como prioritários. Na busca deste objetivo, o Estado chinês, a partir de seu Décimo Plano, promoveu as seguintes ações: i) ajustes na estrutura de produção, estimulando a ampliação e uso de novas tecnologias e fornecendo suporte a grandes corporações de maneira a acelerar suas reestruturações; ii) reorganização interna dos setores, formando grupos empresariais de grande escala de produção, bem como fomentando a formação de empresas de médio e pequeno portes, as quais fabriquem produtos específicos; iii) estímulo à modernização dos sistemas de gestão permitindo a participação privada em empresas estatais; e, iv) reorientação internacional, ingressando na Organização Mundial do Comércio e incentivando a internacionalização de suas empresas (MASIERO e COELHO, 2014, p 145-147)

O que se pretende aqui é demonstrar a sequencialidade com que o governo chinês promoveu sua política industrial e como isso se torna perceptível nos planos quinquenais.

Até o $4^{\circ}$ plano (1953-1975), a preocupação era com indústria pesada, com o estabelecimento de uma base para a industrialização e para o desenvolvimento econômico e também de fortalecer a defesa nacional. Neles, havia uma determinação de metas específicas quanto à produção física, denotando o carater centralizado e imperativo dos planos neste período. Apesar de ter este foco, já são apresentadas algumas metas incentivando a investigação científica e a educação, pois a necessidade de profissionais qualificados para a etapa seguinte era iminente.

Vale salientar que, ainda no $3^{\circ}$ plano quinquenal (1966-1970), os planejadores já começavam a esboçar uma preocupação com a melhoria na qualidade e na variedade de produção, além da criação de infraestrutura que permitisse os planos de desenvolvimento (transporte, energia etc).

A partir do $5^{\circ}$ plano (implementado em 1976), inicia-se uma nova fase planejada do desenvolvimento, onde buscava-se a modernização da economia baseando-se na reforma e abertura econômica. Desde este fato, metas que favorecessem a reforma, abertura econômica e modernização começam a se tornar parte dos planos como,por exemplo, promover criação e aplicação de novas tecnologias e atração de capital estrangeiro.

Depois do $7^{\circ}$ plano quinquenal (1986-1990), o planejamento começa a adotar a denominação de "plano geral para desenvolvimento social e econômico", mostrando a preocupação cada vez maior com o desenvolvimento de fato e não apenas com o crescimento. Metas relacionadas à agenda de reforma, ao equilíbrio e eficiência da economia, da qualidade dos produtos, desenvolvimento da ciência e da educação e qualidade de vida são mencionadas. Além disso, outra novidade é que agora vê-se explicitamente que há uma mudança no foco "da construção para a atualização técnica, reforma e ampliação das empresas existentes" e uma preocupação com a ampliação da abertura econômica (voltada para a competitividade no mercado internacional e para as trocas tecnológicas).

Em seguida, começa a fazer parte do planejamento econômico um caráter mais capitalista à economia chinesa como a descentralização fiscal e as ZEE's. No 9 (19962000) e $10^{\circ}$ (2001-2005) planos vê-se uma nova mudança: questão do sistema empresarial e da competitividade internacional ganhando força como parte da estratégia de desenvolvimento e reforma. $\mathrm{O} 11^{\circ}$ plano (2006-2010) reitera os princípios básicos para o desenvolvimento chinês: o desenvolvimento científico e a sociedade harmoniosa. 
O $12^{\circ}$ plano demonstra uma nova virada estratégica, onde aponta para "novos setores estratégicos", ressaltando a priorização do desenvolvimento científico e tecnológico e dando importância às patentes e à inovação. No $13^{\circ}$ plano, essa nova fase se concretiza e a inovação tecnológica se torna um dos focos centrais do planejamento chinês. Esse foco fica ainda mais claro com o lançamento do Made in China, um plano decenal de política industrial voltado para a endogeneização da inovação tecnológica e inserção na nova revolução industrial: a indústria 4.0.

\section{Made in China - Planejando a indústria da inovação}

Lançado em 2015, e executado concomitantemente com o $13^{\circ}$ Plano Quinquenal, o Made in China é um plano ambicioso da China de construir uma das economias mais avançadas e competitivas do mundo com a ajuda de tecnologias de fabricação inovadoras ("manufatura inteligente"). A estratégia visa praticamente todas as indústrias de alta tecnologia que contribuem fortemente para o crescimento econômico das economias avançadas: automotiva, aviação, máquinas, robótica, equipamentos marítimos e ferroviários de alta tecnologia, veículos que economizam energia, dispositivos médicos e tecnologia da informação, dentre outras (WÜBBEKE et al, 2016).

A promoção e disseminação da tecnologia de "manufatura inteligente" é a peça central da estratégia, que toma emprestado o conceito alemão de Indústria 4.0 e o conceito de "Internet Industrial" formulado nos Estados Unidos. Ao modernizar energicamente os processos industriais mais atrasados do setor manufatureiro da China, o governo chinês espera aumentar a competitividade de suas empresas nos mercados domésticos e impulsionar sua expansão global (WÜBBEKE et al, 2016).

Alguns sugerem que o planejamento estratégico do estado dá à China uma vantagem particular em inovação. As práticas chinesas de "tecno-nacionalismo" promoverão os interesses nacionais da China em detrimento dos parceiros comerciais e o contínuo intercâmbio tecnológico internacional. Cabe mencionar que Wübbeke et at (2016) citam a existência de evidências de que o monopólio estatal sobre os principais setores tecnológicos e financeiros gerou uma corrupção desenfreada e ineficiências no setor público e nas empresas estatais (WÜBBEKE et al, 2016).

De forma resumida, o Made in China concentra-se em: melhorar a qualidade dos produtos fabricados na China; criar marcas próprias da China; construir uma capacidade de fabricação sólida; desenvolver tecnologias avançadas de ponta; pesquisar novos materiais e produzir peças e componentes essenciais dos principais produtos. Essas ações, priorizam dez setores: tecnologia da informação; máquinas de controle numérico de ponta e automação; equipamentos aeroespaciais e de aviação; equipamentos de engenharia marítima e fabricação de embarcações de alta tecnologia; equipamentos ferroviários; veículos que economizam energia; equipamentos elétricos; novos materiais; biomedicina e aparelhos médicos de alto desempenho e equipamentos agrícolas (WÜBBEKE et al, 2016).

Assim como os planos quinquenais, o Made in China tem a pretensão de fazer uma evolução sequencial: procurará substituir gradualmente a tecnologia chinesa em casa - e preparar o terreno para a entrada das empresas de tecnologia nos mercados internacionais. No primeiro período que vai de 2015 a 2025 pretende-se fazer o esforço para a China ser incluída na lista de países com poder de produção global. No segundo período, de 2026 a 2035, a China pretende alçar o nível médio no campo de mundial de energia. Por último, de 2036 a 2049, a China pretende liderar o poder de fabricação no mundo. 
A iniciativa tem um escopo mais amplo na consolidação de indústrias existentes, promovendo a diversidade e ampliando o leque de várias indústrias. Propõe ainda aumentar a cooperação regional, usar Internet of Things (IoT) para realizar fabricação sem fronteiras, inovando em novos produtos e melhorando a qualidade do produto (WÜBBEKE et al, 2016). De acordo Arbix et al (2018) o Made in China "[...] procura combater a ineficiência das empresas industriais chinesas e os efeitos da elevação dos salários e da apreciação da moeda no país, que corroem parte da competitividade da economia." (ARBIX et al, 2018, p 150).

Segundo Briken (2017), o Made in China é, na verdade, um conceito estratégico de desenvolvimento industrial e transformação no contexto mais amplo de reequilíbrio socioeconômico. Centra-se no desenvolvimento de tecnologias centrais (core technologies) através de pesquisa, por um lado, e na reestruturação setorial e transsetorial das cadeias de produção e tecnologia, por outro - padrões similares à política industrial do Japão nos anos 60 e 70 ou conceitos mais antigos de cadeias industriais na França ou outras nações europeias com fortes tradições de desenvolvimento industrial liderado pelo Estado. Ao contrário das abordagens anteriores da política industrial na China, o conceito não aposta na criação de campeões nacionais de empresas estatais reestruturadas, uma estratégia que falhou em setores como o automotivo, o de telecomunicações e outros. Em vez disso, o Made in China retoma o desenvolvimento relativamente bem sucedido de fortes players chineses em mercados de média e alta tecnologia que emergiram "de fora" em setores como sistemas solares, turbinas eólicas, LED, eletrodomésticos ou, mais proeminentemente, telecomunicações e tecnologias de informação avançadas.

Essa orientação para a criação de redes de produção e cadeias de valor lideradas por chineses fortes também se reflete na ênfase dada às infraestruturas de comunicação avançadas, conforme descrito na estratégia Internet Plus. A linguagem desses programas sinaliza uma mudança de concepções mais antigas de "inovação endógena" com foco na construção de empresas chinesas de marca e tecnologias básicas para conceitos de desenvolvimento orientados para a cadeia de valor (BRIKEN, 2017).

O Made in China 2025 reflete a percepção da liderança chinesa de que um modelo de inovação puramente voltado para a exportação (subindo a escada do OEM para o ODM e para o $\mathrm{OBM}^{14}$ ) esgotou seus potenciais para o desenvolvimento industrial da China. A estratégia afasta-se das abordagens de engajamento nas cadeias de valor globais de certas empresas ou setores industriais para mover-se em direção ao desenvolvimento de um sistema relativamente integrado de redes globalizadas de produção e inovação baseadas na China, lideradas por empresas e indústrias chinesas (BRIKEN, 2017).

Como a maioria das outras políticas industriais nacionais na China, o Made in China 2025 é um conceito de cima para baixo, feito por engenheiros e agências de ciência líderes e apresentado em termos de evolucionismo tecnológico. No entanto, o conceito não aborda abertamente as raízes mais profundas das dificuldades da China em integrar a inovação endógena em tecnologias e produtos, por um lado, e a fabricação, por outro.

\footnotetext{
${ }^{14}$ OEM (Original Equipment Manufacturer) fabrica os componentes ou os produtos que serão comprados por uma empresa e depois vendidos sob a marca do comprador. A OBM (Original Brand Manufacturer) é uma empresa que comercializa seus próprios produtos de marca que são os produtos completos ou partes componentes produzidas por uma segunda empresa. Eles vendem os produtos sob sua própria marca, a fim de agregar valor. O OBM será responsável por tudo, incluindo a produção e desenvolvimento, cadeia de fornecimento, entrega e marketing. ODM (Original Design Manufacturer) é responsável por projetar um produto e também pela produção do produto. O ODM continua a vender os produtos que eles projetaram e produziram para atacadistas, eles não vendem diretamente para o mercado.
} 
Tampouco há uma visão de como superar as path dependencies do modelo de crescimento anterior, que estão enraizadas em estruturas de propriedade e relações de poder (BRIKEN, 2017).

Segundo Arbix et al (2018) também corrobora com a ideia de que o caminho da China em direção à inovação tem diversos problemas que não são contemplados pelo Made in China "por seus planos, estratégias e posição relativa no cenário internacional, ainda é um país seguidor e não tecnologicamente desbravador. Seja em termos de pesquisa, de ct\&i ou da capacidade de geração de conhecimento de fronteira, a China tem um longo caminho a percorrer para se transformar efetivamente em um país provedor de tecnologia." (ARBIX et al, 2018)

Como visto, os autores citam algumas dificuldades a serem enfrentadas por esta iniciativa, sejam elas em decorrência da própria trajetória de desenvolvimento da China ou por falhas estratégicas observadas no plano. Entretanto, discutir tais falhas não é o objetivo deste trabalho, mas acredita-se necessário mostrar que elas existem. O que se pretendeu mostrar neste tópico é, portanto, que a política industrial chinesa tem agora outro foco: construir uma economia inovadora, com marcas e design próprios, buscando cada vez mais independência tecnológica e competitividade no cenário internacional.

\section{Considerações finais}

Pode-se perceber com este trabalho que a China conduziu a transformação da sua indústria de forma sequencial. Primeiramente, buscou desenvolver sua indústria de base. Em segundo lugar, passou por uma fase de modernização da sua estrutura industrial para o catching up com as grandes economias absorvendo tecnologia. Por fim, tem feito um esforço crescente em torno do processo de endogeneização da inovação tecnológica a fim de inserir-se na revolução 4.0.

Para tal, a China lançou o plano Made in China 2025, um plano descenal que já prevê os próximos passos até 2049 . Essa iniciativa vem como uma comprovação da nova fase da política industrial chinesa, para a qual houve uma preparação prévia nos planos quinquenais, como pode-se observar.

O Made in China demonstra a mudança da política industrial chinesa o esforço de catching up com as economias desenvolvidas. Além disso, a China precisa reduzir a sua dependência tecnológica e endogeneizar o processo de inovação e de branding.

Essa nova fase exigirá grandes esforços da economia chinesa, mas ao que se viu até aqui, o governo chinês detém ainda grande capacidade de direcionamento da economia e de realização de seus planos.

\section{Referências}

ALBUQUERQUE, E. M. Plano x mercado na história do pensamento econômico: diferentes contextos e lições de quatro rodadas de um grande debate. Belo Horizonte: CEDEPLAR, 2007.

AMARAL, G. C. G. do. Compreendendo as raízes do crescimento econômico da China: uma anatomia das State-Owned Enterprises (SOEs). Trabalho de Conclusão de Curso (Graduacao 
em Relacoes Internacionais) - Faculdade de Filosofia e Ciencias, Universidade Estadual Paulista, Marilia, 2010.

AMATO, Pedro Muñoz. Planejamento. Rio de Janeiro: FGV, 1955. 55 p. Separata de Introducción a la administración pública . México: Fondo de Cultura Económica, 1955. Cap. 3.

ARBIX, G. et al. Made in China 2025 e Industrie 4.0: a difícil transição chinesa do catching up à economia puxada pela inovação. Tempo soc. vol.30 no.3 São Paulo Sept./Dec. 2018

BERTOLDI et al. (2016). Can Economic Transitions Be Planned? China and the 13th Five-Year Plan. European Commission Economic Brief, September 2016.

BRIKEN, K. et al. The new digital workplace: how new technologies revolutionise work. London, Palgrave, 2017.

CHAMBRE, H. A economia planificada. São Paulo: Difusão Europeia do Livro, 1967.

CHANG, Ha-Joon.. State-owned enterprise reform. New York: United Nations DESA, 2007. Disponível em: <https://esa.un.org/techcoop/documents/pn_soereformnote.pdf $>$, acesso em: 05/12/2016.

CHOW, Gregory C. Economic Planning in China. 2011. Disponível em: https://www.princeton.edu/ceps/workingpapers/219chow.pdf

CHVIRKOV, Iú. M. O planejamento econômico de Estado. Rússia: Edições progresso moscovo, 1980.

DELGADO, I. Política industrial na China, na Índia e no Brasil: legados, dilemas de coordenação e e perspectivas. 2015.2 Disponível em:< http://repositorio.ipea.gov.br/bitstream/11058/3632/1/td_2059_.pdf $>$. Acesso em: 20/07/2019

FAN, C. China's Eleventh Five-Year Plan (2006-2010): From "Getting Rich First" to "Common Prosperity". Eurasian Geography and Economics, 2006, 47, No. 6, pp. 708-723.

FAN, Cindy. China's Eleventh Five-Year Plan (2006-2010): From "Getting Rich First" to "Common Prosperity". Eurasian Geography and Economics, 2006, 47, No. 6, pp. 708-723.

FAN, G. e HE, L. China's 12th Five-Year Plan. 2013. Disponível em:

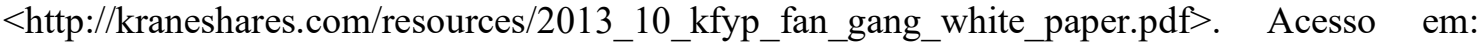
$01 / 12 / 2016$

FAN, Gang e HE, Liping. China's 12th Five-Year Plan. 2013. Disponível em:

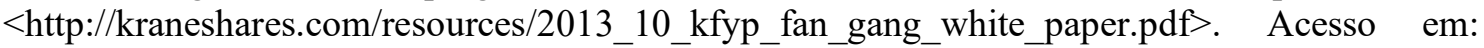
$01 / 12 / 2016$

FERRAZ, G. Estado e planejamento econômico na China: uma análise histórico-econômica com base nos planos quinquenais. Monografia - Ciências Econômicas, Universidade Estadual de Montes Claros, Montes Claros, 2017.

FULONG, Wu. Planning for Growth: Urban and Regional Planning in China. New York \& London, Routledge, RTPI Library Series, 2015.

JABBOUR, Elias Marco Khalil. Projeto nacional, desenvolvimento e socialismo de Mercado na China de hoje. São Paulo, 2010. Tese (Doutorado em geografia) - Faculdade de Filosofia, Letras e Ciências Humanas, Universidade de São Paulo, São Paulo, 2010.

KAPP, Karl W. Economic Regulation and Economic Planning. The American Economic Review, Vol. 29, No. 4 (Dec., 1939), pp. 760-773. Disponível em: <URL: http://www.jstor.org/stable/1804163> Acessado em 13/11/2016 
KENNEDY, S. e JOHNSON, C. Perfecting China, Inc.: The 13th five-year plan. 2016. Disponível em:< https://csis-prod.s3.amazonaws.com/s3fspublic/publication/160521_Kennedy_PerfectingChinaInc_Web.pdf $>$. Acesso em: 05/01/2017.

KENNEDY, Scott e JOHNSON, Christopher K. Perfecting China, Inc.: The 13th five-year plan. 2016. Disponível em: $<\quad \underline{\mathrm{https}: / / \text { csis-prod.s3.amazonaws.com/s3fs- }}$ public/publication/160521_Kennedy_PerfectingChinaInc_Web.pdf $>$. Acesso em: 05/01/2017.

KON, Anita. Subsídios teóricos e metodológicos ao planejamento econômico público. Relatório de pesquisa $\mathrm{n}^{\circ}$ 12/1997. Disponível em: $<$ http://bibliotecadigital.fgv.br/dspace/bitstream/handle/10438/3207/P00172_1.pdf?sequence=1 $>$

LANDAUER, Carl. Theory of national economic planning. University of California, 1947.

LANGE, O. Ensaios sobre planificação econômica. Sao Paulo: Nova Cultural, 1986.

LAWRENCE, Susan V. e MARTIN, Michael F. Understanding China's Political System. Congressional Research $\quad$ Service, 2013.2 Disponível em: $<$ https://fas.org/sgp/crs/row/R41007.pdf > . Acesso em: 30/10/2016

LEPIKSON, João Augusto Pessôa. $\underline{\mathrm{O} \text { socialismo de mercado e o capitalismo de estado: o }}$ afastamento da estratégia chinesa em relação à teoria leninista de transição. (Trabalho de conclusão da Graduação em Economia - UFBA/FCE). Salvador: 2007.

LI, Xing e SHAW, Timothy M. The Political Economy of Chinese State Capitalism. JCIR: VOL. $1, \quad$ No. $\quad 1 \quad$ (2013). Disponível em: < https://journals.aau.dk/index.php/jcir/article/viewFile/218/155>. Acesso em: 20/11/2016

MASIERO, G. e COELHO, D. A política industrial chinesa como determinante de sua estratégia going global. Revista de Economia Política, vol. 34, nº 1 (134), pp. 139-157, janeiromarço.2014.

MATTLIN, M. Chinese strategic state-owned enterprises and ownership control. Asia Papers. Vol. $\quad 4, \quad$ n. $\quad 6, \quad 2009 . \quad$ Disponivel em: $<$ http://www.vub.ac.be/biccs/site/assets/files/apapers/Asia\%20papers/Asia\%20Paper\%204(6).p df> Acesso em: 29 nov. 2011.

PEDROZO, Gustavo Erler. A via chinesa de desenvolvimento e o papel das empresas estatais na dinamização da economia. Marília: Aurora, ano III, n 4 - julho de 2009

SUJIAN, G. The Ownership reform in China: what direction and how far? Journal of Contemporary China, n. 12, ago 2003. Disponivel em: $<$ http://www.tandfonline.com/doi/abs/10.1080/10670560305474\#preview>.

SZAMOSSZEGI, Andrew e KYLE, Cole. An Analysis of State-owned Enterprises and State Capitalism in China. Washington: U.S.-China Economic and Security Review Commission. October 26, 2011. Disponível em: $<$ http://www.uscc.gov/sites/default/files/Research/10_26_11_CapitalTradeSOEStudy.pdf $>$. Acesso em: 13/10/2016

WEBSITE China.org.cn. Five-year Plans. Disponível em: $<$ http://www.china.org.cn/english/features/guideline/156529.htm>. Acesso em: 10/12/2016

WEBSITE China.org.cn. Five-year Plans. Disponível em: $<\mathrm{http}$ ://www.china.org.cn/english/features/guideline/156529.htm $>$. Acesso em: 10/12/2016

WÜBBEKE, Jost et al. Made in China: the making of a high-tech superpower and consequences for industrial countries. 2016. Disponível em: 
$<$ https://www.merics.org/sites/default/files/201807/MPOC_No.2_MadeinChina2025_web.pdf $>$. Acesso em: 23/05/2019.

YASHENG, H. Capitalism with chinesese characteristics. New York: Cambridge University Press, 2008.

ZHANG, Rui e WANG, Zhiyong. "Key Points of the 11th Five-Year Guidelines". China.org.cn, March 7, 2006 [http://www.china.org.cn/english/20061h-160403.htm].

ZHENG, Yongnian. China, an emerging power, is exploring its own development model. China Economist. $\quad$ n. $24, \quad$ jan/fev $2010 . \quad$ Disponivel em: $<$ http://papers.ssrn.com/sol3/papers.cfm?abstract_id=1532106>. 